\title{
Addressing the Anxious Reality of First Year Experience (FYE) In Higher Education: A Comparative Study of Research- Informed Student Support Models in Two UK Business Schools
}

\author{
Carol Brown ${ }^{1}$ and Katharine Brymer ${ }^{2 *}$ \\ ${ }^{1}$ University of Bolton, Greater Manchester, UK \\ ${ }^{2}$ University of Bedfordshire, UK
}

\begin{tabular}{ll} 
ARTICLE INFO & ABSTRACT \\
\cline { 2 - 2 } $\begin{array}{l}\text { Keywords: } \\
\text { First-Year }\end{array}$ & This paper evaluates the reality of first year experience (FYE) in two \\
Anxiety & UK Higher Education Institutions, highlighting a gap between \\
Personal-Tutoring & reported versus experienced anxiety amongst students. The paper \\
Coaching & draws on contemporary literature exploring the value of high quality \\
& discourse, via personal tutoring and coaching models, advocating 'a \\
& whole-of-student, whole-of-organisation' approach to FYE support \\
& within undergraduate business studies. The merits of contrasting an \\
integrative curriculum model of personal tutoring and a coaching \\
process model are considered. Informed by secondary and primary \\
research, both approaches situate rich student-led dialogue central to \\
fully understanding student issues, supporting them through their \\
challenging and transformative first year of study, thus enabling \\
more effective engagement with their learning and support.
\end{tabular}

\section{Introduction}

This paper outlines the challenges faced by what are often referred to as 'non-traditional' entrants in UK Higher Education during what Kift (2014) refers to as their 'make or break' first year of study. A review of literature is undertaken which endeavours to identify ideas, theoretical approaches and thinking as personal tutoring developed and progressed from the 1980 s through the 1990s into the new millennium.

The psycho-social approach of the late 1980's and early 1990's (Lago \& Shipton, 1995) moved pragmatically in the mid 1990's to a handbook methodology, offering a 'how-to' practical approach to supporting students. The strength of the latter focused on practical tutor skills, such as listening and empathy. However, this was also a weakness, with emphasis on practical skills lacking an overarching, strategic dimension, and neglecting the importance of deeper psychological and cultural issues as barriers to learning. As progression rates at many 'new' universities faltered and poor progression mirrored the expanding numbers of people participating in $\mathrm{HE}$ within the UK, an increased interest in this area emerged. The issue of the first year student experience (FYE), and how to support students through their transformative entry period into independent learning, quickly moved up the Higher Education agenda.

Curriculum delivery and structure was identified as a primary factor in retaining and progressing first year students at the end of the first decade of the millennium. Published in 2012, the seminal Thomas Report identified the issues of culture and a 'sense of belonging' as a crucial factor in a student continuing their studies. This paper embraces past work in this area, and endeavours to contribute to the debate by focussing on the levels of anxiety that students feel throughout the course of their first year in HE. The observations offered here contribute to the debate about how first year students can be best supported to facilitate their

* Corresponding Author E-Mail Address: katharine.brymer@beds.ac.uk 
progression to second year study and acknowledge the central role of rich student-centred, dialogue between student and tutor.

\section{Background and Context}

A selection of literature relevant to FYE in Higher Education has been considered and informs this paper. Themes explored include:

- The nature of study in the first year of higher education

- Student expectations and needs

- The value of a holistic approach to support that acknowledges the widest view of the challenges and opportunities of the student journey

- Options for integrated support approaches.

'Helping and Supporting Students' (Earwaker, 1992) will be drawn upon, given its reflexive approach to student support and the different approaches adopted in Higher Education. The juxtaposition of counselling and pastoral care is thought-provoking, emphasizing the importance of clear roles, relationships and boundaries. Earwaker's work is useful in a number of ways, not least for the valuable insight into the psycho-social approach he adopts to new students. He explores the limitations of an over simplified analysis of needs during the initial period of student life, and argues for a more developmental, inclusive approach, which frames the student experience and "continuously optimizes this experience rather than simply removing difficulties from the student or helping the student surmount obstacles" (Earwaker, 1992, p 20).

Earwaker's assertion is that a more holistic understanding of the student, and their challenges and capabilities, is useful, providing an emerging picture of the student as part of a framework of social relationships. The latter paradigm enables tutors to signpost appropriate support from across the HE institution structure to help students respond to a wide variety of learning obstacles appropriately. The issues which trouble first year students at university are rarely simple or straightforward (Kift, 2009; Kift, 2014; Nelson, 2014). Often several problems both perceived and actual - are woven together, and, alongside skills and knowledge shortfalls, commonly include financial issues, a sense of dislocation from established networks (particularly family and friends), enculturation challenges, unmet expectations and a sense of social and academic isolation. These issues often have to be unravelled before they can be dealt with, which is a process that requires time and willing disclosure on the part of the student. The trust of the student, and sensitivity and intuition of the tutor is paramount to this process, as is the availability of confidential space and lack of interruptions.

The issues outlined by Earwaker are not new and continue to resonate in higher education institutions, as increased widening participation brings heightened complexity and challenges. The percentage of the population participating in Higher Education in the UK has risen substantially, from 13\% in the early 1980's (Greenaway \& Haynes, 2003) to 43\% in 2009, and to $49 \%$ in 2015/16 (Department for Business, Innovation \& Skills, 2017). This shift has increased the number of students who are first generation to university and/or with fragmented learner identities (Kasworm, 2009), who juggle conflicting priorities and have limited or inaccurate true knowledge of the reality of HE experiences.

It is important to acknowledge that in the 1980s "there were 38-degree awarding institutions augmented by the institutions awarding CNAA (Council for National Academic Awards) degrees" (Snaith \& Stephenson, 2010), whereas the number of degree awarding institutions in the UK is 139 (http://www.hefce.ac.uk/reg/register/search/Overview) and is currently under audit (Office for Students, 2018). This participation draws in larger numbers from a broader range of socio-economic groups, with available data showing the increase of participants in higher education from the socio-economic classification class 4, 5, 6 and 7 now constitute a third $(30.7 \%)$ of the national student body (HESA, 2013). 
There has been significant reduction in state funding, and, whereas in the past students paid no tuition fees and received a grant, the move to student loans creates an increased need for students to undertake part-time employment alongside their programmes of study to limit their student debt burden. This has implications for the amount of focus, attention and time that students can give to study, introduces barriers to learning and conflicting priorities, which consequently creates a fragmented sense of purpose and identity, increasing the potential problems affecting the continuity of study (Forsyth \& Furlong, 2003, p.1). This has obvious links to student anxiety levels, student engagement, significantly increasing the complexity and level of support required from universities, as student readiness to learn is conflicted by matters of survival.

This research adds strength to Earwaker's stance that it is not productive to view new student life as a smooth optimizing developmental process, but rather as a paradigm characterised by identifiable obstacles. This presents transition support milestones which universities can identify and plan support to help students overcome these obstacles. Acknowledging this position, Earwaker (1992, p24) positively recognises that, although change and transition are part of human life, radical change can take the form of discontinuity. It is this rupture in the thread which runs through the lives of human beings that can threaten an individual's sense of identity. "Moving into new circumstances we are not just having to recover from the shock of the new, but we may actually have to repair damage to the self." He argues that simply repairing to previous self-state is no longer viable nor appropriate, as the student continues to transform through engagement with learning. His questions prioritize the role of academic staff in helping students to maintain continuity during a period of regular and disruptive change to their sense of self.

The challenge for academic tutors is to support the achievement of "an altogether more profound continuity related to a sense of personal identity" (Earwaker, 1992 p.24), that has changed and renders old frames of reference increasingly irrelevant. Magolda (1998, pg. 14) additionally propounds the importance of stewarding 'self-authorship' amongst HE students, as they navigate their emerging sense of self, by collecting, interpreting and analysing information and reflecting on one's own beliefs to form judgements.

This paper acknowledges the importance of dialogue between tutors and students, in prompting them to construct, through dialogue, their reflection on 'distance travelled' and 'challenges met' in navigating their first-year learning journey. Students need help to construct a changed sense of self, through interpretation, sense making and enactment (Weick, 1979), and reflection on their experiences and actions. Moreover, rich tutor contact is essential in encouraging students to disclose the hidden barriers to learning that they may find difficult to share in the classroom. It is argued that the right support can only be provided at those crucial moments of disruption if it considers the full set of challenges and insecurities that the student faces, and from the student's viewpoint.

Earwaker (1992, p24) helpfully raises the question "Is the thread running through our lives a thread of habit or a thread of meaning?" which helps inform the process of connecting with, and understanding, students and the nature of the support they need. Different answers to this question have different implications for the management of the transitionary experience during students in their first year at university and are central to the informed development of appropriate support frameworks.

Considering the operational challenges of effective personal tutoring, in 'Personal tutoring in action', Lago \& Shipton (1995) adopted a pragmatic codification of 'how to' and 'how not to' conduct personal tutoring. The word 'Handbook' appears in the subtitle, which emphasises the importance on clear process and procedure. Highlighting the profound effect of terminology ("we have avoided using the term 'mature' because it infers immaturity in younger students"), and need for mindfulness in regard to language employed, the text highlights 
challenging issues, such as the delivery of bad news, dealing with discipline problems, addressing sexual harassment, and cautions of the dangers of personal tutors imposing their own values on students. Lago \& Shipton's guide to personal tutoring is process driven, highly structured and clearly signposted, offering little reflection on a strategic overview of policy and does not acknowledge the psycho-social paradigmatic approach of Earwaker (1992).

Lago and Shipton's handbook offer a practical approach addressing a variety of different clearly framed prescribed issues, encompassing many dimensions of communication skills, including understanding, empathy, listening, acceptance, paraphrasing, questioning, summarising and considering choices. It is, therefore, an operational text that deconstructs the issues students face, attending to practical needs, but failing to address social and psychological needs. It, therefore, fails to address the complexity of student life, and, as such, falls short of informing a comprehensive structural approach to personal tutoring support. It does, however, highlight the merits of training, orientation and deep learning for academics who are to be involved in the activity, which is helpful.

Personal tutoring has continued to move up the Higher Education agenda, with increased debate in many academic, education management and student forums. For example, 'The Personal Tutoring and Academic Support Conference' (2011) at the Cardiff School of Management, and 'Enhancing Student Success and Retention Academic Advising and Personal Tutoring: A Global Perspective' (June 2013) debated first year transition support into higher education and the contribution of personal tutoring through key milestones.

Students are increasingly conscious of the importance of personal tutoring, as prompted by the National Union of Students NUS Charter on Personal Tutoring (2015), which makes clear student expectations from personal tutors, including supportive personal characteristics and behaviours, and academic, organisational and social support, interpretation of formative feedback and signposting to specialist advice and help.

The role of personal tutoring is also increasingly acknowledged as a crucial enabler of quality provision in higher education, particularly in the first year of study. The report 'Outcomes from institutional audit - Academic and personal advice, guidance and support for students.' (QAA, 2010) draws good practice themes from 59 institutional HEI audit reports, with examples including the value of robust induction, early diagnostic testing, study skills and personal tutoring arrangements (pg 5). Accessibility of staff and ongoing monitoring are also noted throughout. Although many of the examples are bound by the context and nature of individual HEIs, the report offers the examples as "stimulus for reflection rather than a model for emulation" (p.2). Each university must consider the nature of institutional support and resources, departmental priorities and the characteristics and volumes of students, which can, of course, be very different.

Widening participation cohorts present particular challenges, with students who are first generation into higher education disadvantaged by an absence of meaningful guidance based on experience by those who influence them. Such students are particularly vulnerable to lack of confidence and self-worth, and increased fear of failure, and face the danger of not meeting academic standards due to marginalised identities and institutional invisibility (Kasworm, 2010, p.146). "The diverse backgrounds of today's students mean that the role of personal tutor is more important than ever" (Swain, 2008) and a systemic approach situating regular dialogue with a dedicated personal tutor is invaluable.

The importance of first year experience (FYE) is also prominent in higher education planning internationally. The well-attended 'Student Retention and Transition and Success Conference' (STARS, 2016) debated strategic and operational issues associated with FYE, and shared ideas and practice, including the importance of using a whole-of-institution approach, constructing effective support networks, student journey mapping, transition support and diagnostics for key foundation skills. In particular, Luzeckyi (2016) refers to Devlin (2013) in highlighting the 
importance of addressing the issues low socioeconomic students face, by 'bridging sociocultural incongruity', through transitional scaffolding and the student-tutor relationship (Lumsden et al, 2010 - p.21). This is an important consideration with direct implications for student-tutor collaborative dialogue highlighted in this paper.

Johnson (2010) articulates the importance, and challenges, of staff creating a continuous supportive relationship throughout the first year of study. Core to success is linking students with support mechanisms that integrate institutional and departmental support services, learning communities and tutor support. In order to facilitate effective transition, engagement and stable and coherent foundations for learning, Johnson calls for a considered and measured approach to helping students build confidence, independence and self-efficacy. He refers to higher education as a conduit for the development of a student's "sense of citizenship", providing a range of academic, social, cultural and economic spheres of experience informing their development. He argues that the legitimization of challenges and experiences as milestones for reflection and change, rather than evidence of failure, is important, and celebrates the diversity of challenges and experiences, acknowledging their significant value to building self-identity.

Although his work does not specifically focus on personal tutoring, Johnson (2010) adds to the considered exploration of the FYE with the theme of transition. He urges attention be given also to curriculum delivery and structure, focusing usefully on the contribution of effective course design in maximising student engagement and providing effective 'scaffolding support' to new students. The identified characteristics of a 'good First Year Experience' (FYE) are highly relevant to contemporary design of undergraduate Business Studies programmes, HND Business Studies and Foundation level study, particularly the creation of "powerful learning environments" within which students are encouraged to fully participate, drawing on constructivist approaches to learning acknowledged by Kift (2015), Nelson (2005) and Kift (2009).

The NUS Charter on Personal Tutors (2015) includes a number of clauses which can usefully inform personal tutoring practice, encompassing communication, expectations, recognition and flexibility. A major shortcoming, however, is that in two of its clauses, the first and the second, the Charter uses the word 'All'. "All students should be entitled to a named personal tutor" and "All students should meet their tutor at least once a term" can be aspirational, considering the reality of sparse resources and high demands on academic staff in contemporary universities (Shaw \& Ward, 2014). It is argued that, like students, academics also face fragmented identities and competing demands on their time and, whilst supporting the argument for investment in personal tutoring, simply do not have the time nor resources to support the intent, with daily dilemmas on how to spend their time and make room to develop meaningful personal tutoring relationships with 'All' students, alongside other duties and demands. The reality is that staff can only aim to concentrate their efforts on providing rich contact personal tutoring for 'as many students as possible'.

Reflection on pedagogy in Higher Education continues to develop and is constantly evolving. A substantial and significant contribution which focused specifically on student retention are the two HEFCE Reports in March (Summary) and the final report in July 2012 by Professor Thomas. The report identifies that students are "particularly likely to consider leaving (a) after Christmas and (b) during the first semester" (Thomas, 2012, p12). This is supported by wider evidence that the majority of students who do not continue with their studies leave during their first year. The report included qualitative research and identified reasons for leaving which included: "academic issues, feelings of isolation and / or not fitting in" (Thomas, 2012, p12) The report discusses the importance of a sense of 'belonging'. A sense of 'belonging' can be viewed at an individual level, in terms of a student's subjective feeling and how connected they feel to an institution. A sense of belonging is often associated with regular contact and a belief 
that interpersonal relationships have stability, continuity and an affective concern. (Bauminster \& Leary, 1995).

It is important not to misunderstand the direction of thinking here. The Thomas report does not focus on an individualistic view of student retention and success, nor does it adopt an atomized myopic view of students' personal problems. Interestingly the report draws upon the work of sociologists which gained prominence during the 1970's and were associated with what was considered a politically 'left' societal analysis. The following passage outlines the thinking in a concise manner.

"This approach to belonging can be seen to take an individualistic view of student retention and success, thus it is useful here to draw on the work of sociologists, such as Pierre Bourdieu to explore how this works in relation to student backgrounds and institutional cultures. Bourdieu and Passeron's (1977) theories of cultural capital and habitus view the problem structurally, as being embedded in the way that higher education institutions function. 'Cultural capital' incorporates ways of speaking, behaving and interacting, which are learned through interactions with family and social institutions such as home and schools (McLaren, 1989; Meadmore, 1999) and is, therefore, class related. 'Habitus' is the disposition to act in certain ways determined by cultural capital and is the embodiment of cultural capital. Educational institutions have an identifiable habitus (Reay, David and Ball, 2001) which incorporates practices that mutually shape and reshape the institutions with their students, their communities and the wider socio-economic cultures of their catchment areas (Reay, David and Ball, 2001, para 1.3). Students whose habitus is at odds with that of their higher education institution may feel that they do not fit in, that their social and cultural practices are inappropriate and that their tacit knowledge is undervalued, and they may be more inclined to withdraw early" (Thomas, 2012, p13).

Those insights and this analysis is both germane to many post 1992 universities and it is also fundamental to understand the issues and meaningfully address them. Over the past 30 years, participation in higher education has steadily risen from 13\% (Greenaway \& Haynes, 2003) to 48\% (Department for Education, 2016). This has led to different socio-economic groups participating. As the overall number has steadily risen, so proportionally have those students from socio economic groups 1, 2 and 3 declined, while those from 4, 5, 6 and 7 increased. In conjunction with this trend, students from particular socio-economic backgrounds could be seen to be concentrated in specific higher education sectors.

The Russell Group has the largest proportion of its cohort of students who have parents with professional backgrounds, at the beginning and at the end of period of the study. Similarly, the post 1992 group has the smallest.

Table 1.

Total HE student numbers in the UK

\begin{tabular}{llll}
\hline & Russell Group & Pre 1992 & Post 1992 \\
\hline 1996 & $72 \%$ & $63 \%$ & $49 \%$ \\
2010 & $60 \%$ & $49 \%$ & $39 \%$ \\
\hline
\end{tabular}

The declining proportion of students with this background across all types of institution may be attributed to the expansion of the sector" (Snaith \& Stephenson, 2012) over the period referred to in the table 1 . There was a $39 \%$ increase in total HE student numbers in the UK between 1996/7 1,797,081 to 2,501,295 in 2010/11. A decline has taken place since and the most recent participation in HE is 2,280,830 (HESA, 2017), which is a fall of nearly $9 \%$. "Hence similar numbers of students from this background were participating in HE but their numbers constitute a smaller proportion of total participation." (Snaith \& Stephenson, 2012) It can be seen that the data suggests that over $60 \%$ of students in post 1992 institutions are from 
families that do not have professional backgrounds. An alternative view which examines the participation of students from POLAR3 mirrors the data discussed. These students with no previous exposure to Higher Education and coming from a low participation neighborhood represent only $6.13 \%$ of participants in Russell Group universities, while they constitute $15.19 \%$ of students in post 1992 universities (HESA, 2017).

Referring back to the concept of cultural capital and habitus, it is precisely these 'new' participants who would lack the 'appropriate' cultural capital and have a deeply ingrained and inculcated disposition or paradigm which would not sit well with or be 'alien' to, the 'habitus' of a university. 'New' participants are those substantively to be found, not in Russell Group institutions, but in the newer HEIs and particularly in urban conurbation 'modern' universities, such as University of Bolton and London South Bank University.

Informed by research amongst first year business students, this paper shares two approaches to managing the demands and complexity of FYE, with practice that puts rich student-tutor dialogue at its heart - one through an integrative curriculum model of personal tutoring and student-mentorship, and one through the process of coaching.

\section{Anxiety Patterns amongst First Year Students: The investigative approach adopted}

The literature exploring FYE is substantive, and thinking is developing in an organic and holistic manner (Kift, 2016). Whatever the original cause of a student's non-progression, it is argued that those forces are likely to have contributed to a heightened level of anxiety within an individual prior to a decision to withdraw or cease attending. The approach taken here has been to identify and record levels of anxiety within the sample with a view to gaining an insight into, and addressing, the issues.

In order to identify the existence of trends in student anxiety (due to academic, practical, financial and social issues across the FYE), the University of Bolton Business School and London South Bank University Business School conducted a comparative study where students transitioning into second year were asked what they felt were their anxiety levels across their first year of study. It is acknowledged that there are many sophisticated methods available to measure and understand anxiety amongst students (Thawabieh \& Qaisy, 2012). For the purpose of this study, a calendar of the first year of study was provided to participants who were asked to indicate anxiety level $1-10$ for each point in the calendar for their first year of study. It was expected that a trend would emerge, in accordance with earlier research conducted on issues and concerns reported by students at various points in the first semester of first year study (See Graph $1 \&$ Figure 1 - McIntosh \& Brown, 2016). The previous research reports a cohort view and, in line with initial expectations, suggests an easing of concerns and issues as students' progress through their FYE. It was expected, therefore, that the conducted research would report similar student anxiety levels at key points of transition or challenge, such as induction, course start, first assessment, first assessment feedback.

Participants $\mathrm{UoB}=30$

Participants LSBU $=30$ 


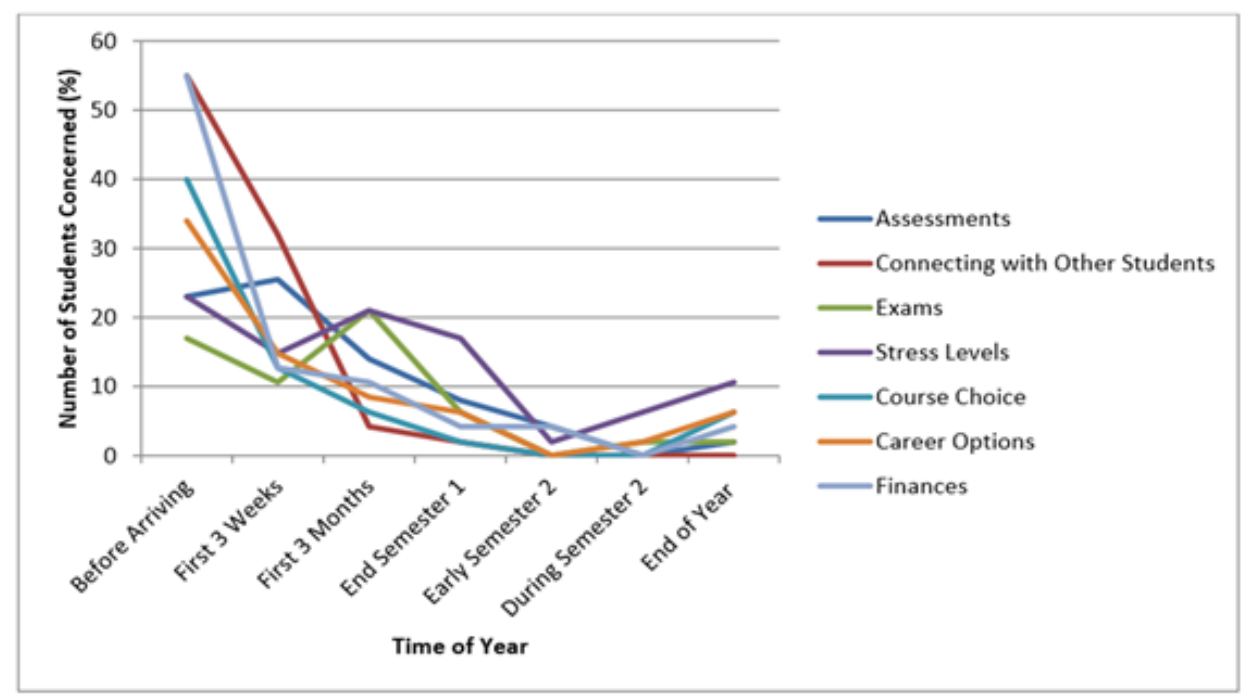

Graph 1. Time of year when students expressed worries or concerns about particularissues (McIntosh \& Brown, 2016)

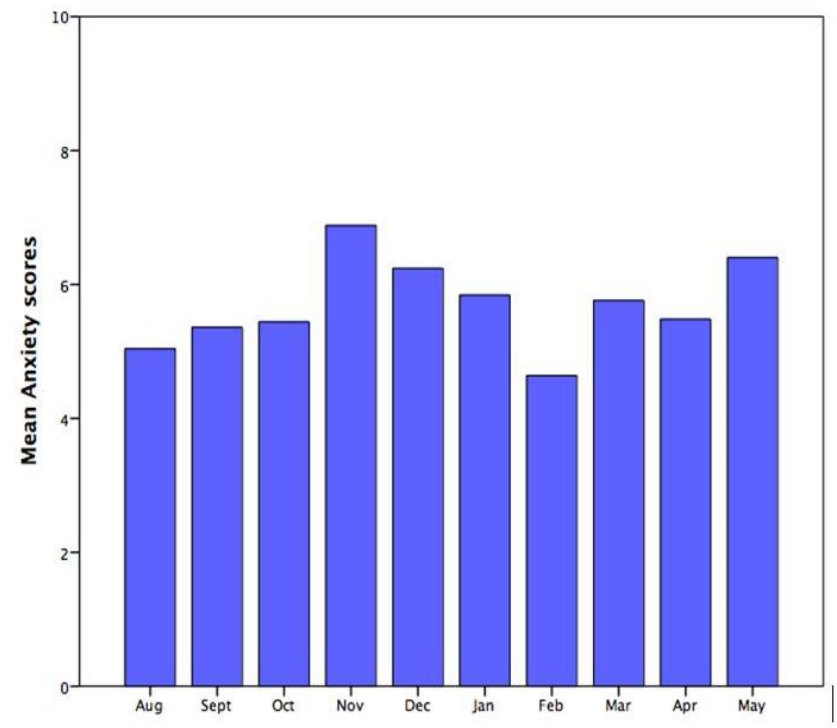

Figure 1. mean anxiety scores of first year business students over the fisrt academic year 2015/16 at University of Bolton

Notably, the following graphs show the unpredictable reality of anxiety experienced by students in the first year at the University of Bolton (UoB) Business School (Graph 2) and London Southbank University (Graph 3), both reported a comparable messy pattern.

What is interesting and surprising is the absence of pattern, mirrored in both Business Schools. It is argued that this clearly demonstrates the importance of rich contact, personal tutoring time to enable student- led dialogue to disclosure of the reality of challenges and barriers faced by FYE students. 


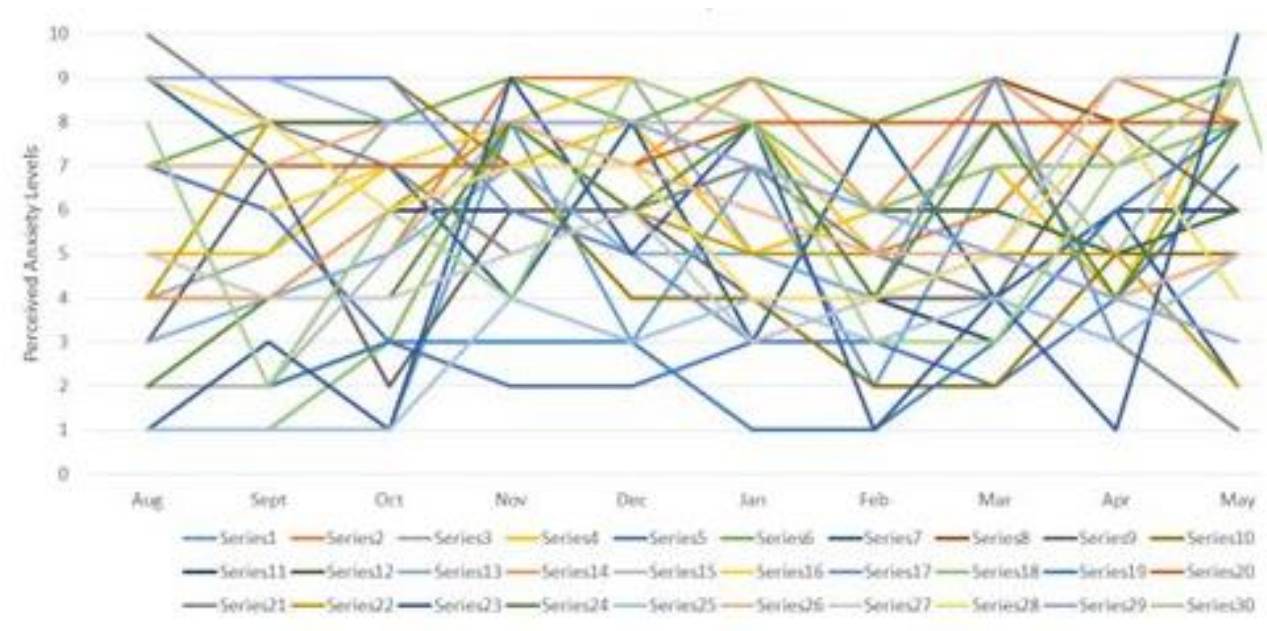

Graph 3. Reflections on anxiety levels $-1^{\text {st }}$ year Business Management Students 2015/16 University of Bolton

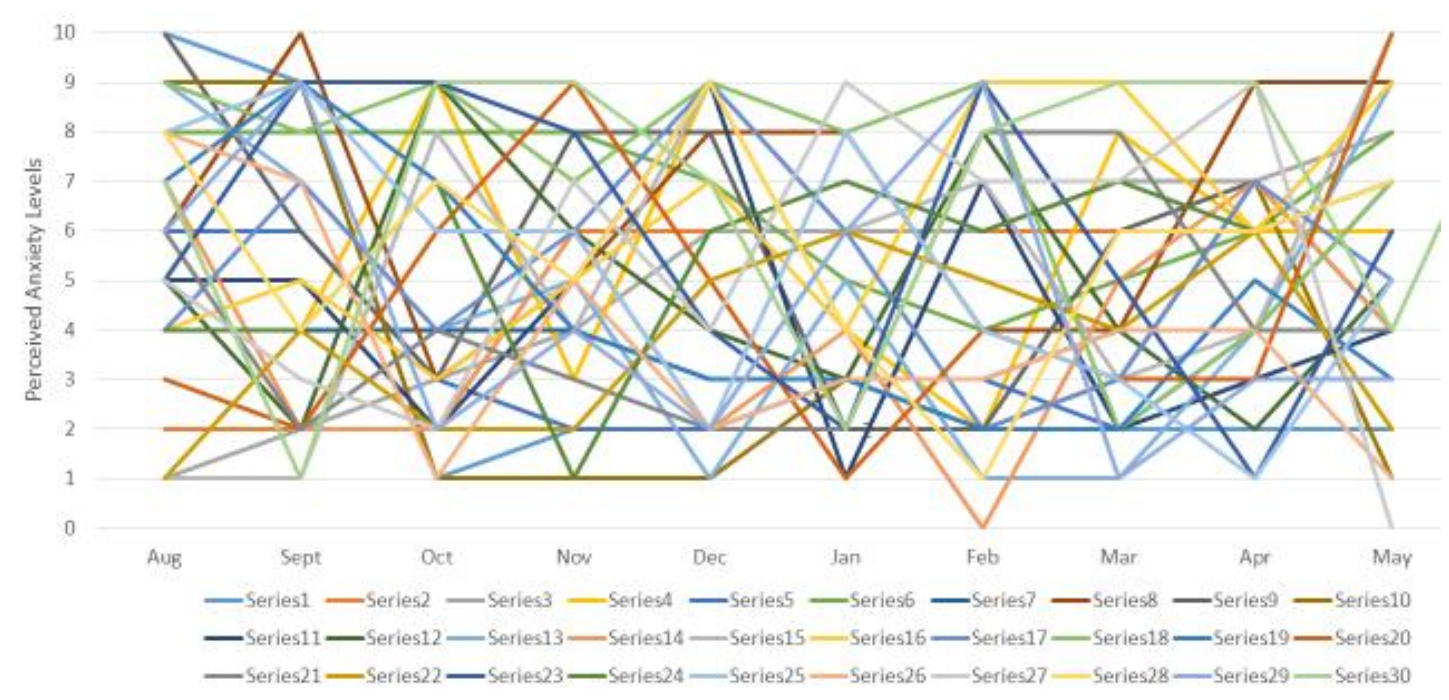

Graph 3. Reflections on anxiety levels $-1^{\text {st }}$ year Business Management Students 2015/16 London Southbank University

The data patterns from individual students show that, rather than a trend pattern emerging, as reported in mean anxiety scores in earlier research shown in Graph 1 and Figure 1 (McIntosh \& Brown, 2016), which would enable the planning of a pattern of predicted interventions, based on mean anxiety for the cohort at key points throughout the FYE, there was enormous variance and that interventions had to be built around the understanding of each individual student to be effective.

These findings support Whannell \& Whannel (2015) who argue that a personalized student experience is important when seeking to support the specific needs and identity issues of students. The challenge, therefore, is to establish support models for FYE that academics are able to deliver to ALL (or MOST) students, given the variety and complexity of needs, and with limited resources.

The systemic support models deployed by the University of Bolton (UoB) and London Southbank University (LSBU) are both highly structured. An integrated approach to personal tutoring, linked to curriculum and supported by student mentor activity, with closely monitored processes, operates within the UoB Business School. In contrast, LSBU employed a coaching approach with eighteen key academic staff in this area. 


\subsection{Bolton Business School Model for First Year Experience Support Personal Tutoring and Student Mentoring embedded in early Academic Skills Curriculum}

In 2016, an inclusive approach was adopted on the BSc (Hons) Business Management programme at Bolton Business School, putting personal tutoring at the heart of the FYE, and anchoring the process within the introductory academic skills module. All students were allocated a personal tutor and the process was monitored. Improvements were made to the induction process where students were introduced to personal tutors on day one.

Initial diagnostics were conducted to identify issues with academic skills, and the data was used to prompt early response by personal tutors to additional support needs and student disengagement. An integrated approach was adopted to personal tutoring in first year cohort, with timetabled group and individual sessions embedded into the academic skills module in the FYE curriculum, over 4.5 hours weekly contact time. Many personal tutors were also module tutors to first year students and tutors signposted students to additional institutional support through the university's Learning Excellence Achievement Pathway (LEAP) providing enhanced academic skills development and wider social, administrative and academic support. The structured approach involved a first-year delivery team coordinated by $1^{\text {st }}$ year Enhanced Personal Tutor, and personal tutors, who were selected for their empathetic approach, taught the core academic skills module in the first semester module in order to increase rich contact time with tutees. This provided enhanced opportunity for student-led dialogue between student and tutor to help increase the understanding of individual capacity, capability and barriers to learning (academic, social, practical, financial). Smaller seminar/tutorial class sizes were adopted, providing a low ratio of students to tutors.

Peer Assisted Study Support sessions (PASS) were also embedded into the FYE curriculum, with six volunteer students from the $2^{\text {nd }}$ and $3^{\text {rd }}$ year trained to lead structured student-only mentoring sessions to $1^{\text {st }}$ years fortnightly. The sessions provided academic skills practice and gave further opportunity for students to reveal issues, without tutor involvement. Students were monitored weekly on academic, social and well-being issues, with tutors and student mentors sharing insights disclosed in classes, in student mentor sessions and during personal tutoring interactions. In addition, Ideas, Concerns and Expectations (ICE) research took place across the cohort at mid-point and at the end of first semester module, to identify issues and monitor perceived anxiety.

Additional emphasis was added to attendance and engagement, with regular learner review meetings consolidating all data and insight on individual learners and enabling escalation, with learner engagement agreements formalised with those students 'at risk' of non-engagement and leaving.

Early indications show an increase in attendance, retention and achievement levels. Rich dialogue and an integrated approach to sharing the insights on individual students, gained by tutors and student mentors, prompted early interventions, and one-to-one support was personalised, informed by the knowledge of individual situations and issues experienced by the students. Identification and understanding of complex fragmented student identities and needs was developed in an environment of trust and disclosure, through a dialogical process involving learners, tutors, module tutors and student mentees.

Achievement, attendance and performance data in subsequent years will help validate the approach further.

\subsection{London South Bank University Business School Model for First Year Experience Support - Embedded Coaching and Staff Development Model}

In 2016, London South Bank University Business School decided to realign its student support and move away from personal tutoring and towards coaching. This realignment followed some 
discussion where thinking coalesced around the increasingly popular coaching approach. Some of the thematic drives of coaching are considered to be: -

- Self-awareness - group members established common understanding of boundaries and explored participant identity and disposition, both prior to and post the coaching process.

- Exploration of thoughts, feelings and the mechanisms of communication - through scheduled coaching sessions.

- Developed appreciation of the coaching process - appreciating that coaching skills are an effective communication and decision-making partnership tool, helping tutors to connect with students. These skills contribute to learners becoming meaningful team members and collaborators.

- Developed practical coaching skills to facilitate personal awareness of learners, encouraging them to identify the link between their dispositions and their values and ambitions.

- Promoted coaching to help individuals identifying their strengths, weaknesses, drives and aspirations, helping to facilitate the change process and precipitate action. Hence this acts as a liminal stage prior to moving forward and planning the next action. (Field \& Morgan Klein, 2010)

- Anchoring the concept of personal effectiveness within the coaching process, enabling positive habit formation, together with empathy, compassion and the skills associated with the establishment of boundaries (Graydin, LSBU, 2017)

The scheme was launched with the provision of a coaching training programme for participating staff. This took place over a period of three months and consisted of three blocks of two days. Eighteen staff members participated in the training. Coaches were drawn from a range of academic disciplines including marketing, information systems and economics, as well as some non-academic areas. Certified training was delivered by an externally sourced provider, Graydin, and a number of participants have since progressed to working towards obtaining ILM Level 3 Coaching awards.

Coaching was delivered via the Professional Competencies module which is one of six 20 credit modules on the Common First Year for undergraduates in the Business School. This included students undertaking a variety of programmes which included BA (Hons) Business Management, BSc (Hons) Economics, BA (Hons) Marketing, BA (Hons) Accounting \& Finance and HND Business Management, and a variety of combined degrees, including BA (Hons) Business Management with Accounting, BA (Hons) Business Management with Economics and BA (Hons) Business Management with Retail. The coaching sessions were provided to students during both Semester 1 and Semester 2 in the following pattern: -

\begin{tabular}{cc}
\hline Contact & Week Number \\
Semester 1 & \\
3 & 3 \\
3 & 6 \\
3 & 9 \\
3 & 12 \\
3 & 13 \\
Semester 2 & \\
2 & 4 \\
2 & 8 \\
2 & 11 \\
\hline
\end{tabular}


The coaching sessions were integrated within the Professional Competencies module. This module has a weekly contact of five hours. The coaches did not necessarily teach on the module, although the majority of those who taught on the module undertook the coaching training (seven out of the teaching team of eight). The early signs are that the coaching approach is addressing the wide ranging and disparate impediments to learning and retention of students within the Business School at London South Bank University. Crucially the issues of cultural capital identified and discussed by Thomas (2012), and the wider issue of 'fragmented identity' are raised and tackled in a positive future focused way through the development of coaching skills, with its emphasis on identity, values, awareness and personal effectiveness.

\section{Conclusion}

This paper sets out two approaches to building an effective FYE in a business school environment and argues that, given the individual and complex nature of the challenges students face, rich dialogue for disclosure of issues and personal circumstances of students is key to effective on-boarding and proving the right support first year of study to students with fragmented identities, as they progress through a period of challenge and transformation. Successful FYE is best characterised by ongoing student monitoring, good feedback, transparent assessment and good teaching, with a systemic approach to student support (personal tutoring / coaching) as a core conduit for understanding student issues, accessing the right support which is tailored around their individual their personal first year journey and transforming sense of identity.

It is interesting that both models of support are anchored in the development of academic skills and have been designed to increase interaction to provide richer, more focused dialogue with individuals, rather than a cohort planned approach. UoB adopts a more positivist, organic integrated team approach, with higher year volunteer student mentees working alongside the curriculum team and personal tutors, to prompt open, student-led disclosure through dialogue of the barriers to learning. Regular monitoring meetings provided a 'whole of student' view of needs and circumstance, which informed interventions for those at risk of achievement and oncompletion of the first year of study.

The LSBU model addresses the cultural capital and fragmented learner identity issues more fully through a clearly structured coaching approach, that builds awareness of 'self-authorship' (Magolda, 1999), with regular student-tutor discussion prompting students to explore their sense of identity, values and personal effectiveness.

There is great advantage in both models being used to marshal results and assessment feedback and putting them central to the personal tutoring/coaching processes, and overall the learnings provided in the comparison of the two models are extensive and valuable.

Higher Education institutions tend to organise resources around what the perceived key areas of challenge or obstacles are for students. These include assessment, examinations, finance and connecting or engaging with other learners. Historic thinking has tended to place these challenges in a chronological timeline. This would begin with the issue of finance, be followed by the issues of building relationships or connecting with others and lead on to assessment. However, the research undertaken and reported in this work suggests this historical thinking may not be reflective of reality today.

An appropriate, meaningful approach to supporting students with the characteristics discussed within this paper may require a modification to past practice. It is possible that an ongoing open dialogue, without an assumed focus on the part of academic staff, may be of advantage. The driver here is exploration of the students' view, enabled by student led dialogue. This approach is time consuming and involves availability of academics with an appropriate disposition in the task of listening to individuals. 
The challenge of cultural capital, highlighted by Thomas (2012) offers a view that an impediment to retention and progression may not be fragmented 'learner identity' but more pointedly fragmented 'identity'. The importance of stewarding students through their first year of study, towards the concept of effective 'self-authorship' (Kegan, 1994) or 'personal effectiveness" (Graydin, 2017) is central to successful provision of comprehensive support. The value of students learning to be "self-initiating, self-correcting, self-evaluating.... and take responsibility" for what happens to them is unquestionable.

The models in this paper offer differing yet valid approaches to support for undergraduate entrants. Whichever model is chosen, both are grounded in rich contact and discourse for disclosure. Sadly, the ability to fully support the transformation towards independence of learning and independence of identity lies hostage to fortune, enabled, or otherwise, by the availability of time allocation in academic contracts. Therein lies an issue of considerable continued debate in the increasingly commercialized models of Higher Education.

\section{References}

Australasia annual conference (pp. 225-235). Melbourne, Australia.

Department for Education (2017) Participation Rates for Higher education: Academic Years 2006/2007 - 2015/16 (Provisional). [Online]. Available at: https://assets.publishing.service. gov.uk/government/uploads/system/uploads/attachment_data/file/648165/HEIPR_PUBLI CATION_2015-16.pdf [Accessed 3 May 2018].

Devlin, M (2013) Bridging socio-cultural incongruity: conceptualising the success of students from low socio-economic status backgrounds in Australian higher education. Studies in Higher Education Vol. 38, Issue 6, p.939-949

Earwaker, J., (1992) Helping and Supporting Students. Rethinking the Issues. Taylor and Francis Publishers, 1900 Frost Road, Suite 101, Bristol, PA 19007-1598.

experience. Proceedings of the Higher Education Research and Development Society of

Field, J. \& Morgan-Klein, N. (2010) Student hood and identification: higher education as a liminal transitional space, $40^{\text {th }}$ Annual SCUTREA Conference, 6- $8^{\text {th }}$ July 2010

Forsyth, A. \& Furlong, A. (2003) Losing Out? Socioeconomic disadvantage and experience in further and higher education. Bristol: The Policy Press on behalf of the Joseph Rowntree Foundation.

Graydin \& LSBU. (2017) Be Effective Facilitator Handbook, $2^{\text {nd }}$ edition. London: London South Bank University.

HESA (2017) https://www.hesa.ac.uk/data-and-analysis/students Accessed :29 .05.17.

HESA (2017) https://www.hesa.ac.uk/data-and-analysis/performance-indicators/releases/ 2015-16-widening-participation Accessed 29 .05.17.

Higher Education Funding Council for England (2017) Register of HE providers [Online] Available from http://www.hefce.ac.uk/reg/register/search/Overview/ [Accessed 7 May 2017].

Hixenbaugh, P. \& Thomas, L. (2006). Personal Tutoring in Higher Education. Trentham: Open University.

Kasworm, C. (2009) Adult Learners in a Research University: Negotiating Undergraduate Student Identity. Adult Education Quarterly. [Online] 60(2) 143-160. Available from http://journals.sagepub.com. DOI: 10.1177/0741713609336110 
Keagan, R. (1994) In over our heads: The mental demands of modern life. Cambridge, MA:Harvard University Press.

Kift, S. (2014) Student success: why first year at uni is a make-or-break experience. The Conversation. [Online] 19 February. Available from https://theconversation.com/studentsuccess-why-first-year-at-uni-is-a-make-or-break-experience-21465. [Accessed 5 March 2017].

Kift, S. (2016) A decade of Transition Pedagogy: A quantum leap in conceptualising the firstyear experience. HERDSA Review of Higher Education, Vol.2 p52-86

Kift, S., \& Nelson, K. J. (2005). Beyond curriculum reform: Embedding the transition

Kift, S., (2009). Articulating a transition pedagogy to scaffold and to enhance the first year student learning experi3ence in Australian higher education. Final report for ALTC Senior Fellowship Program. Sydney, Australia: Australian Learning and Teaching Council. Retrieved from http://olt.gov.au/resource-first-year-learning-experience-kift-2009 .

Largo, C \& Shipton, G., (1995) Personal tutoring in action: a handbook for staff who work with and support students. Sheffield University Counselling Service.

Lumsden, E., Mcbryde-Wilding, H. \& Rose, H (2010) Collaborative practice in enhancing the first-year student experience in Higher Education. Enhancing the Learner Experience in Higher Education vol 2 Number 1 [Online] Available at: http://nectar.northampton.ac.uk/3462/1/Lumsden20103462.pdf

Luzeckyj, A. \& Rankin, A., (2016) Conference resource - Portal to the STARS - a practical resource package for staff teaching first year students STARS 2016 Accessed online at http://unistars.org/papers/STARS2016.pdf.

Magolda, B. (2001) Making Their Own Way - Narratives for transforming higher education to promote self-development. Sterling, VA: Stylus Publishing

McIntosh, E., \& Brown, C. (2016). Articulating a pedagogy for transition and early intervention - insights from Bolton Business School. Solstice CLT Conference 2016.

Nelson, S. (2014) The First Year in Higher Education - Where to from here? The International Journal of the First Year in Higher Education. Vol5 Issue 2 pp 1-20.

NUS (2015) NUS Charter on personal tutors. http://www.nusconnect.org.uk/resources/nuscharter-on-personal-tutors [Online]. Accessed 25/10/16

Office for Students (2018) The OfS register. https://www.officeforstudents.org.uk/advice-andguidance/the-register/the-ofs-register/ [Online]. Accessed 3 May 2018

Ormskirk,UK: Edgehill University.

Personal Tutoring and Academic Support Conference (2011) at the Cardiff School of Management and Enhancing Student Success and Retention Academic Advising and Personal Tutoring: A Global Perspective (June 2013) Cardiff University

QAA (2010) Outcomes from institutional audit: Academic guidance, support and

Shaw, C. \& Ward, L. (2014) Dark thoughts: why mental illness is on the rise in academia. The Guardian. [Online] 6 March 2014. Available at : https://www.theguardian.com/highereducation-network/2014/mar/06/mental-health-academics-growing-problem-pressureuniversity. [Accessed 5 May 2017].

Snaith, J. \& Stephenson, K (2012) Much ado about nothing: The HE League Tables in perspective, University Business, ISSN 1751-9209. 
Snaith, J. \& Stephenson, K (2010) The Student Experience: through the looking glass, University Business, Issue 32 ISSN 1751-9209

supervision, and personal support and guidance. [Online] Available at: http://www.academicaudit.net/uploads/2/6/1/5/26158328/academicguidance.pdf

Swain, H. (2008) The Personal Tutor. Times Higher Education. [Online] Available at: https://www.timeshighereducation.com/news/the-personal-tutor/210049.article. [Accessed 5 May 2017]

Thomas, L. (2012) Building student engagement and belonging in Higher Education at a time of change: final report from the What Works? Student Retention \& Success programme. Higher Education Funding Council for England/Higher Education Academy. Accessed on line at https://www.heacademy.ac.uk/resources/detail/what-works-student-retention/ What_works_final_report.

Weick, K. E. (1979) The Social Psychology of Organizing. (2 $2^{\text {nd }}$ ed.) Reading MA: McGrawHill.

Whannell, R. \& Whannel, P. (2015) Identity theory as a theoretical framework to understand attrition for university students in transition. Student Success 6(2), 43-52. doi: 10.5204/ssj. v6i2.286 